\title{
Use of High-Flow Nasal Cannula for Acute Dyspnea and Hypoxemia in the Emergency Department
}

\author{
Nuttapol Rittayamai MD, Jamsak Tscheikuna MD, Nattakarn Praphruetkit MD, and \\ Sunthorn Kijpinyochai MD
}

\begin{abstract}
BACKGROUND: Acute dyspnea and hypoxemia are 2 of the most common problems in the emergency room. Oxygen therapy is an essential supportive treatment to correct these issues. In this study, we investigated the physiologic effects of high-flow nasal oxygen cannula (HFNC) compared with conventional oxygen therapy (COT) in subjects with acute dyspnea and hypoxemia in the emergency room. METHODS: A prospective randomized comparative study was conducted in the emergency department of a university hospital. Forty subjects were randomized to receive HFNC or COT for $1 \mathrm{~h}$. The primary outcome was level of dyspnea, and secondary outcomes included change in breathing frequency, subject comfort, adverse events, and rate of hospitalization. RESULTS: Common causes of acute dyspnea and hypoxemia were congestive heart failure, asthma exacerbation, COPD exacerbation, and pneumonia. HFNC significantly improved dyspnea $(2.0 \pm 1.8$ vs $3.8 \pm 2.3, P=.01)$ and subject comfort $(1.6 \pm 1.7$ vs $3.7 \pm 2.4, P=.01)$ compared with COT. No statistically significant difference in breathing frequency was found between the 2 groups at the end of the study. HFNC was well tolerated, and no serious adverse events were found. The rate of hospitalization in the HFNC group was lower than in the COT group, but there was no statistically significant difference $(50 \%$ vs $65 \%, P=.34)$. CONCLUSIONS: HFNC improved dyspnea and comfort in subjects presenting with acute dyspnea and hypoxemia in the emergency department. HFNC may benefit patients requiring oxygen therapy in the emergency room. Key words: high-flow nasal oxygen cannula; oxygen therapy; dyspnea; hypoxemia; emergency room. [Respir Care 2015;60(10):1377-1382. (C) 2015 Daedalus Enterprises]
\end{abstract}

\section{Introduction}

Acute dyspnea with accompanying hypoxemia is a major problem in emergency departments. Common causes of this condition include acute pulmonary edema, pneu-

Drs Rittayamai and Tscheikuna are affiliated with the Division of Respiratory Diseases and Tuberculosis, Department of Medicine, and Drs Praphruetkit and Kijpinyochai are affiliated with the Department of Emergency Medicine, Faculty of Medicine Siriraj Hospital, Mahidol University, Bangkok, Thailand.

This study was supported by Grant R015531049 from the Faculty of Medicine Siriraj Hospital, Mahidol University. The authors have disclosed no conflicts of interest. This is Thai Clinical Trials Registry identifier TCTR20140618002.

Correspondence: Nuttapol Rittayamai MD, Division of Respiratory Diseases and Tuberculosis, Department of Medicine, Faculty of Medicine Siriraj Hospital, Mahidol University, 2 Prannok Road, Bangkoknoi District, Bangkok 10700, Thailand. E-mail: nuttapol.rit@mahidol.ac.th. monia, and exacerbation of chronic obstructive airway diseases such as asthma and COPD. Specific therapy for the underlying disease is the mainstay of treatment. However, oxygen therapy is an essential supportive treatment to correct hypoxemia and alleviate breathlessness. ${ }^{1}$ Oxygen supply via a nasal cannula or non-rebreathing mask is routinely used, but these methods may be inadequate to support patients' increased work of breathing, particularly if they require a high inspiratory flow (range of 30-120 L/min in acute respiratory failure). ${ }^{2}$ Furthermore, variations in $\mathrm{F}_{\mathrm{IO}_{2}}$ occur with conventional oxygen therapy (COT), and delivered $\mathrm{F}_{\mathrm{IO}_{2}}$ depends on oxygen flow and the patient's breathing pattern. ${ }^{3}$

High-flow nasal cannula (HFNC) is a heated, humidified, high-flow oxygen delivery system that can generate

DOI: $10.4187 /$ respcare. 03837 
total gas flows of up to $60 \mathrm{~L} /$ min with an adjustable $\mathrm{F}_{\mathrm{IO}_{2}} \cdot{ }^{4}$ This device can provide some PEEP that may help to improve oxygenation and counteract the effects of intrinsic PEEP on work of breathing and that may act by washing out oropharyngeal dead space. ${ }^{5}$ It may also help to reduce inspiratory resistance and facilitate secretion clearance from humidified gas. ${ }^{4} \mathrm{HFNC}$ has demonstrated benefits in terms of improving dyspnea and oxygenation in subjects with acute respiratory failure, ${ }^{6}$ after endotracheal extubation, ${ }^{7}$ and in post-cardiac surgery subjects, ${ }^{8}$ In addition, a recent study demonstrated that subjects receiving HFNC after extubation had a lower re-intubation rate compared with subjects receiving standard oxygen therapy. ${ }^{9}$ However, the benefit of HFNC for patients with acute dyspnea and hypoxemia in the emergency department is limited. Thus, the aim of this study was to compare the physiologic effects of HFNC versus COT on subjects with acute dyspnea and hypoxemia in an emergency department.

\section{Methods}

\section{Subjects and Study Design}

A prospective randomized comparative study (Thai Clinical Trials Registry identifier TCTR20140618002) was conducted from May 2012 to November 2012 in an emergency department of the Faculty of Medicine Siriraj Hospital in Bangkok, Thailand, to investigate the effects of HFNC in terms of physiologic changes (dyspnea, breathing frequency, oxygenation, and comfort), adverse events, and hospitalization rate compared with COT in subjects with acute dyspnea and hypoxemia. This study was approved by the Siriraj institutional review board (protocol 041/2555[EC1]), and subjects or their relatives provided informed consent.

\section{See the Related Editorial on Page 1522}

The study enrolled subjects $\geq 18$ y old who developed acute dyspnea with hypoxemia (breathing frequency $>24$ breaths/min and $\mathrm{S}_{\mathrm{pO}_{2}}<94 \%$ on room air). Subjects with hemodynamic instability, need for invasive mechanical ventilation, chronic respiratory failure with long-term oxygen supplementation, decreased level of consciousness (Glasgow Coma Scale score $<13$ ), and lack of cooperation or who were pregnant were excluded.

\section{Device Description}

The HFNC device (Optiflow, Fisher \& Paykel Healthcare, Auckland, New Zealand) consists of an air-oxygen blender that can generate air-oxygen flow of up to $60 \mathrm{~L} / \mathrm{min}$ with $\mathrm{F}_{\mathrm{IO}_{2}}$

\section{QUICK LOOK}

\section{Current knowledge}

Heated-and-humidified $\mathrm{O}_{2}$ delivered by high-flow nasal cannula reduces ventilatory requirements by flushing the anatomic dead space and improves oxygenation by meeting inspiratory flow demands. A low level of end-expiratory pressure may also be generated, further enhancing oxygenation. Heat and humidity allow high flows to be tolerated and improve patient comfort.

\section{What this paper contributes to our knowledge}

Heated-and-humidified high-flow $\mathrm{O}_{2}$ resulted in less dyspnea and better comfort compared with conventional $\mathrm{O}_{2}$ therapy (COT) in subjects presenting to the emergency room with acute dyspnea and hypoxemia. Mean $\mathrm{O}_{2}$ flow was $35 \mathrm{~L} / \mathrm{min}$ in the high-flow group and $6 \mathrm{~L} / \mathrm{min}$ in the COT group. There were no differences in hospital admission rates between the groups.

adjusted between 0.21 to 1.00 and heated humidification (MR850 pass-over humidifier, Fisher \& Paykel Healthcare). The air-oxygen mixture at $37^{\circ} \mathrm{C}$ was delivered via a singlelimb heated inspiratory circuit through a nasal cannula. COT was applied through a nasal cannula or a non-rebreathing mask per emergency physician preference.

\section{Protocol}

The eligible subjects were randomized into 2 groups with a blind envelope pull. In the HFNC group, oxygen was delivered at an inspiratory flow of $35 \mathrm{~L} / \mathrm{min}$, and $\mathrm{F}_{\mathrm{IO}_{2}}$ was adjusted to achieve an $\mathrm{S}_{\mathrm{pO}_{2}}$ of $\geq 94 \%$ within the first $5 \mathrm{~min}$ and was continued for $60 \mathrm{~min}$. In the COT group, oxygen was supplied via a nasal cannula or non-rebreathing mask at a flow of $3-10 \mathrm{~L} / \mathrm{min}$ to maintain an $\mathrm{S}_{\mathrm{pO}_{2}}$ of $\geq 94 \%$ for $60 \mathrm{~min}$.

\section{Data Collection}

Baseline demographic and clinical data were collected. Physiologic variables, including breathing frequency, heart rate, mean arterial pressure, and $\mathrm{S}_{\mathrm{pO}_{2}}$, were recorded immediately after applying each intervention and then at 5, $10,15,30$, and 60 min. Dyspnea levels and subject comfort were assessed using a numerical rating scale ranging from 0 to $10 .{ }^{10}$ Hospital admission rate, adverse events, and other specific adjunctive treatments such as diuretics, inhaled medication, systemic corticosteroids, and antibiotics were recorded. 


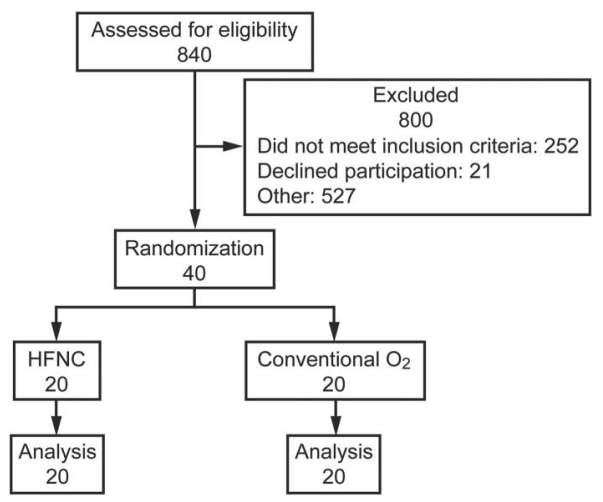

Fig. 1. Flow chart. HFNC = high-flow nasal cannula.

\section{Outcome Variables}

The primary outcome was the effect of HFNC on dyspnea levels compared with COT. The secondary outcomes were the effects on breathing frequency, other physiologic variables (mean arterial pressure and heart rate), subject comfort, adverse events, and hospitalization rate.

\section{Statistical Analysis}

On the basis of a previous study on HFNC in acute respiratory failure, ${ }^{6}$ we expected that HFNC would improve dyspnea by $25 \%$ in subjects with acute dyspnea and hypoxemia compared with COT. Assuming a 2 -sided $\alpha$ value of .05, the estimated sample size was 38 subjects with a power of $90 \%$. Data were analyzed with an intention-to-treat approach. All statistical analyses were performed using SPSS 18 (SPSS, Chicago, Illinois). The results were expressed as mean $\pm \mathrm{SD}$, frequency, or percentage. Normality of the distribution was assessed with the Kolmogorov-Smirnov test. Categorical variables were compared by chi-square tests. For changes in continuous variables between groups (time effect of 0-60 min), a mixed between/within-subject analysis of covariance (using age, variable at baseline, bronchodilator, and corticosteroid as covariates), followed by a post hoc test, was performed. Missing data for a subject in the HFNC group due to withdrawal from the study and a subject in the COT group due to a technical issue were addressed using an expectation-maximization technique. $P<.05$ was considered statistically significant.

\section{Results}

\section{Baseline Characteristics}

Forty subjects were enrolled in this study (Fig. 1). One subject in the HFNC group withdrew immediately after applying the device due to intolerance, and one subject in the COT group had missing data because of a technical issue. The mean age was $64.6 \pm 14.9 \mathrm{y}$, and the mean Acute Physiology and Chronic Health Evaluation II score was $15.1 \pm 3.5$. Baseline characteristics were similar between the 2 groups, except the heart rate in the HFNC group was lower than in the COT group $(93.5 \pm 16.2$ vs $107.7 \pm 24.0$ beats $/ \mathrm{min}, P=.04)(\mathrm{Ta}-$ ble 1). Common causes of acute dyspnea and hypoxemia were congestive heart failure, pneumonia, and asthma and COPD exacerbations. No difference in the emergency department diagnosis or co-treatment was found between the 2 groups.

\section{Clinical Parameters and Outcomes}

Mean total air-oxygen flow and $\mathrm{F}_{\mathrm{IO}_{2}}$ in the HFNC group were $35.5 \pm 2.2 \mathrm{~L} / \mathrm{min}$ and $0.45 \pm 0.09$, respectively. In the COT group, oxygen was delivered at a mean total flow of $5.6 \pm 3.0 \mathrm{~L} / \mathrm{min}$. HFNC significantly improved the level of dyspnea compared with COT. This effect was demonstrated as early as 5 min after applying the HFNC up through the end of the study, except at 30 min (Fig. 2). At the end of the study, subjects who received HFNC had a better comfort level compared with those who received COT. HFNC significantly reduced breathing frequency during the study period (from 10 to $30 \mathrm{~min}$ ), although no significant difference in breathing frequency was found between the 2 groups at the end of the study. The heart rate in the HFNC group was significantly lower compared with the COT group at the end of the study. No significant differences in mean arterial pressure and $\mathrm{S}_{\mathrm{pO}_{2}}$ were observed between the 2 groups (Table 2).

\section{Adverse Events and Hospitalization Rate}

No serious adverse events occurred. Three subjects in the HFNC group reported minor events: unpleasant smell, too warm temperature, and chest discomfort. No subject was intubated or received noninvasive ventilation. There was a downward trend in the rate of hospitalization in the HFNC group compared with the COT group, but this difference was not statistically significant $(50 \%$ vs $65 \%$, $P=.34)$.

\section{Discussion}

To our knowledge, this is the first randomized study to compare HFNC and COT in the emergency department. The main outcome demonstrated that HFNC significantly improved the level of dyspnea and that this effect was immediate. This finding was consistent with other studies on subjects with acute respiratory failure. Roca et $\mathrm{al}^{6} \mathrm{com}-$ pared HFNC and COT in a randomized cross-over study and demonstrated that HFNC improved dyspnea and com- 
Table 1. Baseline Characteristics of the Groups of Randomized Subjects

\begin{tabular}{|c|c|c|c|}
\hline Characteristic & $\operatorname{HFNC}(n=20)$ & $\operatorname{COT}(n=20)$ & $P$ \\
\hline Age, mean \pm SD y & $65.6 \pm 14.4$ & $63.6 \pm 15.7$ & .26 \\
\hline Females, $n(\%)$ & $11(55.0)$ & $14(70.0)$ & .51 \\
\hline \multicolumn{4}{|l|}{ Underlying disease, $n(\%)$} \\
\hline Cardiovascular & $7(35.0)$ & $3(15.0)$ & .14 \\
\hline Respiratory & $8(40.0)$ & $10(50.0)$ & .38 \\
\hline Diabetes mellitus & $5(25.0)$ & $9(45.0)$ & .16 \\
\hline Hypertension & $10(50.0)$ & $10(50.0)$ & .62 \\
\hline Other & $5(25.0)$ & $6(30.0)$ & .50 \\
\hline \multicolumn{4}{|l|}{ Diagnosis in emergency department, $n(\%)$} \\
\hline Congestive heart failure & $9(45.0)$ & $5(25.0)$ & .16 \\
\hline Asthmatic attack & $2(10.0)$ & $5(25.0)$ & .20 \\
\hline COPD exacerbation & $3(15.0)$ & $2(10.0)$ & .50 \\
\hline Pneumonia & $3(15.0)$ & $6(30.0)$ & .23 \\
\hline Other & $3(15.0)$ & $2(10.0)$ & .50 \\
\hline \multicolumn{4}{|l|}{ Co-treatment, $n(\%)$} \\
\hline Diuretics & $8(40.0)$ & $5(25.0)$ & .25 \\
\hline Bronchodilators & $12(60.0)$ & $14(70.0)$ & .37 \\
\hline Corticosteroids & $7(35.0)$ & $7(35.0)$ & .63 \\
\hline Antibiotics & $4(20.0)$ & $5(25.0)$ & .50 \\
\hline \multicolumn{4}{|l|}{ Initial physiologic parameters } \\
\hline Breathing frequency, mean $\pm \mathrm{SD}$ breaths/min & $31.7 \pm 5.5$ & $32.1 \pm 5.0$ & .81 \\
\hline Mean arterial pressure, mean $\pm \mathrm{SD} \mathrm{mm} \mathrm{Hg}$ & $100.4 \pm 22.9$ & $104.6 \pm 16.9$ & .51 \\
\hline Heart rate, mean $\pm \mathrm{SD}$ beats/min & $93.5 \pm 16.2$ & $107.7 \pm 24.0$ & .04 \\
\hline $\mathrm{S}_{\mathrm{pO}_{2}}$, mean $\pm \mathrm{SD} \%$ & $85.9 \pm 9.0$ & $88.7 \pm 4.5$ & .23 \\
\hline
\end{tabular}

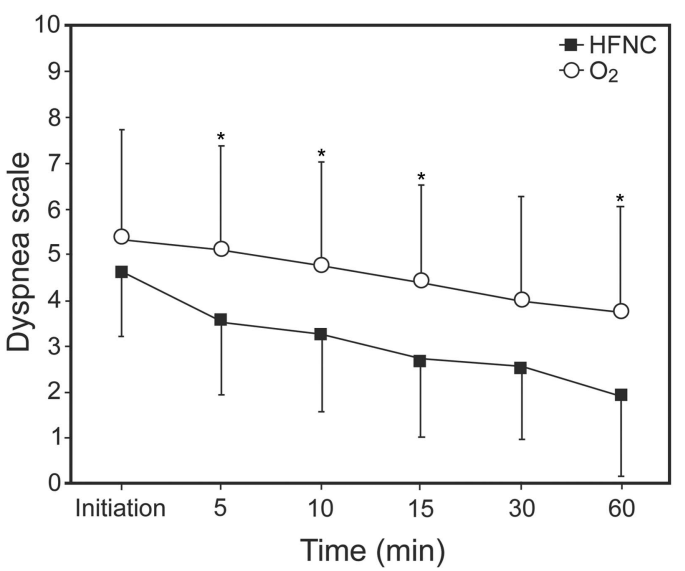

Fig. 2. Change in level of dyspnea assessed using a numerical rating scale $(0-10)$ between high-flow nasal cannula (HFNC) and conventional oxygen therapy. HFNC significantly improved dyspnea as early as $5 \mathrm{~min}$ after application, and this effect continued to the end of the study, except at 30 min. ${ }^{*} P<.05$.

fort. In addition, HFNC was better tolerated and provided better comfort compared with COT. An observational study by Lenglet et $\mathrm{al}^{11}$ showed that HFNC decreased dyspnea scores compared with COT in subjects with acute respiratory failure presenting to an emergency department. Fur- thermore, Schwabbauer et al $^{12}$ found that HFNC significantly reduced dyspnea and improved comfort compared with noninvasive ventilation in subjects with hypoxemic respiratory failure. In addition, the subjects in the present study tolerated HFNC very well, and no serious adverse events occurred during the study period. Furthermore, subjects who received HFNC trended toward reduced hospitalization, but this was not found to be statistically significant.

Improvement of dyspnea by HFNC can be explained by several mechanisms, including the high gas flow matching subjects' demand, ${ }^{13}$ decreased pharyngeal dead space, $, 14,15$ low levels of positive airway pressure, ${ }^{16-19}$ improved thoracoabdominal synchrony, ${ }^{20}$ and reduced symptoms of mucosal dryness with heated-and-humidified gas. ${ }^{21-23}$ In addition, all of these mechanisms also explain why HFNC improved gas exchange and subject comfort. The advantage of HFNC in terms of improving dyspnea, subject comfort, and oxygenation has also been noted in other subject populations, such as post-cardiac surgery ${ }^{8}$ and postendotracheal extubation subjects, ${ }^{7,9}$ and during fiberoptic bronchoscopy. ${ }^{24}$

Several studies demonstrated that HFNC reduced breathing frequency and also improved oxygenation in subjects 
Table 2. Comparing Clinical and Physiologic Parameters for the HFNC and COT Groups at the End of the Study

\begin{tabular}{lcrr}
\hline \hline \multicolumn{1}{c}{ Parameter } & HFNC & COT & $P$ \\
\hline Dyspnea scale score, mean $\pm \mathrm{SD}$ & $2.0 \pm 1.8$ & $3.8 \pm 2.3$ & .01 \\
Breathing frequency, mean $\pm \mathrm{SD}$ breaths/min & $26.0 \pm 6.2$ & $27.5 \pm 4.9$ & .82 \\
Mean arterial pressure, mean $\pm \mathrm{SD} \mathrm{mm} \mathrm{Hg}$ & $88.7 \pm 10.9$ & $101.0 \pm 24.8$ & .31 \\
$\mathrm{Heart}$ rate, mean $\pm \mathrm{SD}$ beats/min & $91.7 \pm 19.3$ & $101.6 \pm 24.2$ & .04 \\
$\mathrm{~S}_{\mathrm{pO}_{2}}$, mean $\pm \mathrm{SD} \%$ & $96.8 \pm 2.5$ & $97.6 \pm 2.0$ & .13 \\
Comfort scale score, mean $\pm \mathrm{SD}$ & $1.6 \pm 1.7$ & $3.7 \pm 2.4$ & .01
\end{tabular}

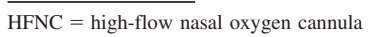

$\mathrm{COT}=$ conventional oxygen therapy

with acute respiratory failure. ${ }^{25-28}$ In the present study, we found that HFNC significantly reduced breathing frequency during the study period, but there was no significant difference at the end of the study. This could be explained by the effect of specific treatments such as bronchodilator medications or diuretics, which had time to act and modified the pathophysiology of the subjects' presentation. ${ }^{29-33}$

Patients receiving HFNC should be closely monitored using parameters similar to those used during noninvasive ventilation. Messika et $\mathrm{al}^{34}$ found that HFNC failure was associated with lower $\mathrm{P}_{\mathrm{aO}} / \mathrm{F}_{\mathrm{IO}}$ and higher breathing frequency and Simplified Acute Physiology Score II. In addition, in a retrospective observational study on subjects with acute respiratory failure, Kang et $\mathrm{al}^{35}$ found that HFNC failure led to delayed endotracheal intubation and worse clinical outcomes. In the present study, no subject was intubated or received noninvasive ventilation because they were less sick compared with the subjects in the abovementioned studies. Thus, appropriate selection and frequent re-evaluation of patients during HFNC use will help to improve outcomes, particularly in the emergency department.

This study has some limitations. First, there was a $1.5-\mathrm{h}$ delay on average between the screening period and protocol initiation. Second, we did not measure delivered $\mathrm{F}_{\mathrm{IO}_{2}}$ in the COT group because this technique was difficult to perform in the emergency department. Third, arterial blood gases were not measured during the study. This was an important limitation for comparing gas exchange between the 2 groups and the potential changes in $\mathrm{P}_{\mathrm{aCO}}$ from oxygen therapy, particularly in subjects with COPD.

\section{Conclusions}

In conclusion, HFNC resulted in less dyspnea and better comfort in comparison with COT in subjects presenting to the emergency department with acute dyspnea and hypoxemia. This device may benefit patients requiring oxygen therapy in the emergency department.

\section{ACKNOWLEDGMENTS}

We thank Mr Suthipol Udompanthurak MSc (Clinical Epidemiology Unit, Department of Health Research and Development, Faculty of Medicine Siriraj Hospital, Mahidol University, Bangkok, Thailand) for his contribution to the statistical analysis.

\section{REFERENCES}

1. O'Driscoll BR, Howard LS, Davison AG. Emergency oxygen use in adult patients: concise guidance. Clin Med 2011;11(4):372-375.

2. L'Her E, Deye N, Lellouche F, Taille S, Demoule A, Fraticelli A, et al. Physiologic effects of noninvasive ventilation during acute lung injury. Am J Respir Crit Care Med 2005;172(9):1112-1118.

3. O'Driscoll BR, Howard LS, Davison AG, British Thoracic Society. BTS guideline for emergency oxygen use in adult patients. Thorax 2008;63(Suppl 6):vi1-vi68.

4. Ricard JD. High flow nasal oxygen in acute respiratory failure. Minerva Anestesiol 2012;78(7):836-841.

5. Dysart K, Miller TL, Wolfson MR, Shaffer TH. Research in high flow therapy: mechanisms of action. Respir Med 2009;103(10):1400-1405.

6. Roca O, Riera J, Torres F, Masclans JR. High-flow oxygen therapy in acute respiratory failure. Respir Care 2010;55(4):408-413.

7. Rittayamai N, Tscheikuna J, Rujiwit P. High-flow nasal cannula versus conventional oxygen therapy after endotracheal extubation: a randomized crossover physiologic study. Respir Care 2014;59(4): 485-490.

8. Corley A, Caruana LR, Barnett AG, Tronstad O, Fraser JF. Oxygen delivery through high-flow nasal cannulae increases end-expiratory lung volume and reduces respiratory rate in post-cardiac surgical patients. Br J Anaesth 2011;107(6):998-1004.

9. Maggiore SM, Idone FA, Vaschetto R, Festa R, Cataldo A, Antonicelli $\mathrm{F}$, et al. Nasal high-flow versus Venturi mask oxygen therapy after extubation. Effects on oxygenation, comfort, and clinical outcome. Am J Respir Crit Care Med 2014;190(3):282-288.

10. Bausewein C, Farquhar M, Booth S, Gysels M, Higginson IJ. Measurement of breathlessness in advanced disease: a systematic review. Respir Med 2007;101(3):399-410.

11. Lenglet H, Sztrymf B, Leroy C, Brun P, Dreyfuss D, Ricard JD. Humidified high flow nasal oxygen during respiratory failure in the emergency department: feasibility and efficacy. Respir Care 2012; 57(11):1873-1878.

12. Schwabbauer N, Berg B, Blumenstock G, Haap M, Hetzel J, Riessen R. Nasal high-flow oxygen therapy in patients with hypoxic respiratory failure: effect on functional and subjective respiratory parameters compared to conventional oxygen therapy and non-invasive ventilation (NIV). BMC Anesthesiol 2014;14:66. 
13. Lee JH, Rehder KJ, Williford L, Cheifetz IM, Turner DA. Use of high flow nasal cannula in critically ill infants, children, and adults: a critical review of the literature. Intensive Care Med 2013;39(2): 247-257.

14. Kernick J, Magarey J. What is the evidence for the use of high flow nasal cannula oxygen in adult patients admitted to critical care units? A systematic review. Aust Crit Care 2010;23(2):53-70.

15. Groves N, Tobin A. High flow nasal oxygen generates positive airway pressure in adult volunteers. Aust Crit Care 2007;20(4):126131.

16. Parke R, McGuinness S, Eccleston M. Nasal high-flow therapy delivers low level positive airway pressure. Br J Anaesth 2009;103(6): 886-890.

17. Parke RL, Eccleston ML, McGuinness SP. The effects of flow on airway pressure during nasal high-flow oxygen therapy. Respir Care 2011;56(8):1151-1155.

18. Ritchie JE, Williams AB, Gerard C, Hockey H. Evaluation of a humidified nasal high-flow oxygen system, using oxygraphy, capnography and measurement of upper airway pressures. Anaesth Intensive Care 2011;39(6):1103-1110.

19. Parke RL, McGuinness SP. Pressures delivered by nasal high flow oxygen during all phases of the respiratory cycle. Respir Care 2013; 58(10): 1621-1624.

20. Itagaki T, Okuda N, Tsunano Y, Kohata H, Nakataki E, Onodera M, et al. Effect of high-flow nasal cannula on thoraco-abdominal synchrony in adult critically ill patients. Respir Care 2014;59(1):70-74.

21. Chanques G, Constantin JM, Sauter M, Jung B, Sebbane M, Verzilli $\mathrm{D}$, et al. Discomfort associated with underhumidified high-flow oxygen therapy in critically ill patients. Intensive Care Med 2009; 35(6):996-1003.

22. Chidekel A, Zhu Y, Wang J, Mosko JJ, Rodriguez E, Shaffer TH. The effects of gas humidification with high-flow nasal cannula on cultured human airway epithelial cells. Pulm Med 2012;2012;380686.

23. Cuquemelle E, Pham T, Papon JF, Louis B, Danin PE, Brochard L. Heated and humidified high-flow oxygen therapy reduces discomfort during hypoxemic respiratory failure. Respir Care 2012;57(10):15711577.

24. Lucangelo U, Vassallo FG, Marras E, Ferluga M, Beziza E, Comuzzi $\mathrm{L}$, et al. High-flow nasal interface improves oxygenation in patients undergoing bronchoscopy. Crit Care Res Pract 2012;2012;506382.
25. Sztrymf B, Messika J, Bertrand F, Hurel D, Leon R, Dreyfuss D, Ricard JD. Beneficial effects of humidified high flow nasal oxygen in critical care patients: a prospective pilot study. Intensive Care Med 2011;37(11):1780-1786.

26. Sztrymf B, Messika J, Mayot T, Lenglet H, Dreyfuss D, Ricard JD. Impact of high-flow nasal cannula oxygen therapy on intensive care unit patients with acute respiratory failure: a prospective observational study. J Crit Care 2012;27(3):324.e9-324.e13.

27. Parke RL, McGuinness SP, Eccleston ML. A preliminary randomized controlled trial to assess effectiveness of nasal high-flow oxygen in intensive care patients. Respir Care 2011;56(3):265-270.

28. Roca O, Pérez-Terán P, Masclans JR, Pérez L, Galve E, Evangelista A, Rello J. Patients with New York Heart Association class III heart failure may benefit with high flow nasal cannula supportive therapy: high flow nasal cannula in heart failure. J Crit Care 2013;28(5):741746.

29. Ring-Larsen H, Henriksen JH, Wilken C, Clausen J, Pals H, Christensen NJ. Diuretic treatment in decompensated cirrhosis and congestive heart failure: effect of posture. BMJ 1986;292(6532):13511353.

30. Ellison DH. Diuretic therapy and resistance in congestive heart failure. Cardiology 2001;96(3-4):132-143.

31. Raimondi AC, Schottlender J, Lombardi D, Molfino NA. Treatment of acute severe asthma with inhaled albuterol delivered via jet nebulizer, metered dose inhaler with spacer, or dry powder. Chest 1997; 112(1):24-28

32. Karpel JP, Aldrich TK, Prezant DJ, Guguchev K, Gaitan-Salas A, Pathiparti R. Emergency treatment of acute asthma with albuterol metered-dose inhaler plus holding chamber: how often should treatments be administered? Chest 1997;112(2):348-356.

33. Levin DC, Little KS, Laughlin KR, Galbraith JM, Gustman PM, Murphy D, et al. Addition of anticholinergic solution prolongs bronchodilator effect of $\beta_{2}$ agonists in patients with chronic obstructive pulmonary disease. Am J Med 1996;100(1A):40S-48S.

34. Messika J, Ben Ahmed K, Gaudry S, Miguel-Montanes R, Rafat C, Sztrymf B, et al. Use of high-flow nasal cannula oxygen therapy in subjects with ARDS: a 1-year observational study. Respir Care 2015; 60(2):162-169.

35. Kang BJ, Koh Y, Lim CM, Huh JW, Baek S, Han M, et al. Failure of high-flow nasal cannula therapy may delay intubation and increase mortality. Intensive Care Med 2015;41(4):623-632.

This article is approved for Continuing Respiratory Care Education credit. For information and to obtain your CRCE

(free to AARC members) visit www.rcjournal.com 